\title{
LA ENSEÑANZA VIRTUAL EN LA UNIVERSIDAD EN TIEMPOS DE PANDEMIA
}

\author{
Dr. José Antonio Legua Cárdenas
}

En tiempos de pandemia por la enfermedad covid-19 se hace necesario encontrar nuevas estrategias educativas para mejorar la enseñanza virtual y a la vez la urgente la necesidad de gestionar los recursos para cumplir las necesidades académicas programadas para cada periodo de estudios.

En estos tiempos de pandemia urge adaptarnos a nuevos sistemas educativos, que al respecto Cervi et al (2020) nos indica que la COVID-19 ha evidenciado la urgente transformación que demandan los sistemas educativos tradicionales y la importancia de poseer una estrategia educativa virtual, así como un alumnado y un profesorado con habilidades y competencias para la enseñanza y el aprendizaje en el ciberespacio. La irrupción de este virus planetario ha dejado constancia de las exigencias de una pandemia a las instituciones educativa: flexibilidad, plataformas, metodologías y contenidos adaptados a unos intercambios formativos mediados porlas pantallas.

El problema sanitario que ha afectado drásticamente a la universidad pública, ha tenido que reaccionar para adaptarse a esta nueva realidad para pasar de las tradicionales actividades presenciales a las virtuales que según Cáceres et al (2020) expresan que esta educación, mediada por tecnología, ha solicitado de un esfuerzo de aprendizaje exprés para muchos docentes. En lo concerniente a la enseñanza virtual Cervantes et al (2020) explican que, como resultado, los contextos mediados por un acceso a la educación a distancia, a través de tecnologías digitales, han sido desiguales; en particular, para los grupos sociales de mayor vulnerabilidad.

En esta nueva realidad educativa es una preocupación de las autoridades universitarias para que todos los alumnos puedan tener acceso y oportunidad en las mismas condiciones pada continuar su formación profesional en este orden de ideas Fontana et al (2020) nos explican que, en efecto, esta presencialidad remota ha dejado de considerar las particularidades y las condiciones de accesibilidad para garantizar la inclusión, la equidad y la calidad en la formación universitaria.

Con el objetivo de contextualizar la actual situación y las implicancias de la enseñanza virtual Gonzales -Calvo et al (2020) expresan que desde La suspensión de las actividades docentes presenciales para dar paso a la virtualización ha supuesto que el profesorado y el alumnado tengan una elevada presión, tanto en su trabajo como en la adaptación al nuevo escenario. Además, la transición a esta docencia online ha sido abrupta, desconociendo los largos procesos de formación, de rediseño de asignaturas y de infraestructuras que soporten la demanda de la tele-enseñanza.

\section{REFERENCIASBIBLIOGRAFICAS}

Cervi, L., Tusa, F. y Parola, A. (2020). Educación en tiempos de pandemia: reflexiones de alumnos y profesores sobre la enseñanza virtual universitaria en España, Italia y Ecuador. RLCS, Revista Latina de Comunicación Social, $78,1-21$

Cáceres, J., Jiménez, A. y Martín, M. (2020). Cierre de Escuelas y Desigualdad Socioeducativa en Tiempos del Covid-19. Una Investigación Exploratoria en Clave Internacional. Revista Internacional de Educación para la Justicia Social, 9(3).

Cervantes, E. y Gutiérrez, P. (2020). Resistir la Covid-19. Intersecciones en la Educación de Ciudad Juárez, México. Revista Internacional de Educación para la Justicia Social, 9(3).
Fontana, A., Herrera, S., Leiva, B., y Montero, J. (2020). El Proyecto UNA Educación de Calidad en el contexto de la COVID 19. Revista Electrónica Educare, 24. Recuperado $d$

https://www.revistas.una.ac.cr/index.php/EDUCARE/arti cle/view/14225RLCS, Revista Latina de Comunicación Social, 78, 1-21[Investigación] DOI: 10.4185/RLCS-20201466| ISSN 1138-5820|Año 2020 Recibido: 23/07/2020.

González, G., Barba, R., Bores, D. y Gallego, V. (2020). Aprendiendo a Ser Docente Sin Estar en las Aulas. La COVID-19 Como Amenaza al Desarrollo Profesional del Futuro Profesorado. International and Multidisciplinary Journal of Social Sciences, 2(9), 152-177. http://doi.org/10.17583/rimcis.2020.5783 